\title{
Research on Course Integration of Mobile Internet Device Programming (Android Program Development)
}

\author{
Hongchang $\mathrm{Ke}^{1, \mathrm{a}^{*}}$ and Degang Kong ${ }^{1, \mathrm{~b}}$ \\ ${ }^{1}$ School of Computer Technology and Engineering, Changchun Institute of Technology, \\ Changchun 130012, China \\ $\mathrm{a}^{*}$ kehongchang1981@163.com, b183665891@qq.com
}

Keywords: Mobile internet; Android; Teaching model

\begin{abstract}
With the rapid development of mobile devices and the Internet, Android, as an operating system for smart mobile devices, has been applied to many regions, and mobile Internet device programming (Android program development) is also gradually developing. It is aimed at the teaching features of current Android programming courses. The in-depth inquiry has analyzed the problems existing in the traditional teaching model, and has pointedly put forward reform measures that are consistent with the teaching integration of the course, which also achieved good results.
\end{abstract}

\section{Introduction}

With the rapid development of mobile internet, cloud computing and big data, mobile internet can enable persons to obtain information and services from the internet anytime, anywhere, quickly and easily. Mobile devices have become necessities of life and run on various traditional desktop browsers. The information systems and Internet applications have been redeveloped and ported to mobile devices for synchronized use. In the mobile device market, Android and IOS which are two smart terminal operating systems have played an important role and occupied almost all the market share. But IOS due to its closeness and limitations has the higher requirements of developers. While Android is part of the Linux operating system and application development is based on the Java language, its portability and openness are high, and specialists for Java EE can quickly move to Android development. Its market prospects are very large. The mobile internet device programming (Android programming) course is a very practical course. How to improve practical ability of students in the course of teaching is worth exploring. This is also the basic requirement of the application-oriented undergraduate teaching. Therefore, students should be guided by active projects to actively and initially learn, so that students can not only master knowledge, but also apply knowledge comprehensively.

Please keep a second copy of your manuscript in your office. When receiving the paper, we assume that the corresponding authors grant us the copyright to use the paper for the book or journal in question. Should authors use tables or figures from other Publications, they must ask the corresponding publishers to grant them the right to publish this material in their paper.

\section{Teaching Status of "Android Programming" Course}

As a new course, Android programming is characterized by strong practicality and rapid development. As a result, its teaching content system, teaching implementation methods, and assessment methods must be gradually updated and become the focus of attention. Some college teachers have conducted some beneficial explorations, but the effect is not well.

Lack of Curriculum Guidance. Many local application-oriented colleges and universities are trying to reform some of the computer programming and application courses. For example, they are not relying solely on PPT and teaching materials in teaching. Instead, they join classroom examples and simulation exercises, and to a certain extent they do exercise practical hands-on ability of students. However, these cases are designed around specific knowledge points. There are not many considerations for practical applications. There is a lack of connection between cases and lack of 
practicality. It is easy to lead students to lose their enthusiasm for learning. Some students even follow the pace of teachers to complete parts of the exercises, but still little is known about the complete project, lack of project development and practical capabilities.

The Assessment Method is not New and cannot Reflect the Features of Students. Android programming courses cannot adopt traditional assessment methods, that is, focus on results, ignore the process. The traditional assessment methods are mainly through the end-of-term examination paper examinations. The evaluation of student performance is also relatively simple and one-sided. This kind of examination still evaluates students through the test scores, and assesses the specific knowledge and practical ability of students, which is not enough. Although the final total score is the weighting of the usual results and the final grades, it still can't reflect the student's usual learning process and cannot reflect the students' mastery of Android development skills. When teachers only look at scores and do not look at the process, students with better practical ability in the exam will not perform well and their grades will be unsatisfactory; students with poorer performance will also get quite good results because of hardly working before the exam. Most of our teachers are unwilling to see it.

Practical Teaching Method Sole and Monotonous. In the traditional Android programming teaching, most of the practical course is to allow students to complete the corresponding case, and the teacher does not or rarely design and arrange open thematic discussion or complete project development and design, so that the entire course will be studied. The atmosphere is relatively quiet, the enthusiasm for learning has not been completely mobilized, and the links between the projects are less and do not serve as a guide.

\section{Exploring the Teaching Integration of Android Programming}

Constructing an Integrated Teaching Model. The Android program is a very practical course. In order to allow students to experience the learning more quickly and better, we put the course teaching in the laboratory, and design/build a teaching integrated teaching module composed of theory explanation, case presentation, and student practice. Taking 90 minutes of one teaching hour as an example, the time for theoretical teaching and case presentation in each teaching module is controlled within 20 minutes. Immediately after completion, the students are allowed to practice the corresponding case project. Through timely practical exercises, they can find problems and deepen the experience so that students can quickly grasp relevant knowledge points.

Selection and Implementation of Comprehensive Project. In the exploration of teaching reform, we will try to select a comprehensive case in the teaching process and divide it according to the module of knowledge. It is impossible to cover all knowledge points in one case. While the major case is selected, some small cases with teaching also need to be chosen. The choice of the main case is very important. It must be familiar with the students, not too complicated and can cover important Android knowledge points, Android App projects with certain practicalities, for example, we can choose the student management system case, covering, making calls and Send SMS App, Sqlite database application, Android basic UI operation, Android Activity component application and ListView core control application. Knowledge can be integrated.

Reform and Implementation of Course Assessment Methods. Android programming is a very practical course. We did not use the conventional assessment method based on written test scores. Instead, we use an integrated assessment method that combines process assessment, practice assessment and written test assessment. The ratio is set to 4:3:3. The process assessment mainly assesses students' attendance, completion of each practical task, and the completion of homework; the written test mainly assesses students' mastery of the main theoretical knowledge points; practice assessment requires students to complete a small Android application project individually or in groups. , Through the project demonstration, defense and design report comprehensive assessment of students' mastery of theoretical knowledge and engineering application capabilities. 


\section{Summary}

This paper deeply investigated the features of the Android programming curriculum, analyzed the problems existing in the traditional teaching model, and proposed targeted reform measures that were consistent with the subject's teaching integration and had achieved good results. In the future teaching, we should constantly improve the teaching concepts and methods according to the content updates, implement and master the development of Android, improve and supplement the teaching content of the course, and focus on cultivating practical hands-on capabilities of students to meet the needs of society for IT talents to cultivate professional and technical talents.

\section{References}

[1] Y. J. Fu: Education Teaching Forum. Vol. 3 (2016) No.11 p.147.

[2] B. C. Zhong and R. Yuan: Computer Knowledge and Technology. Vol. 23 (2016) p. 141.

[3] L. H. Yu: Journal of Hunan University of Science and Engineering. Vol. 36 (2015) No.10, p. 97.

[4] Z. B. Wu, L. Yuan and C. Y. Hu: Modern computer. Vol. 5(2015) p. 17.

[5] S. G. Wu: Computer Education. Vol. 7(2009) p. 104. 